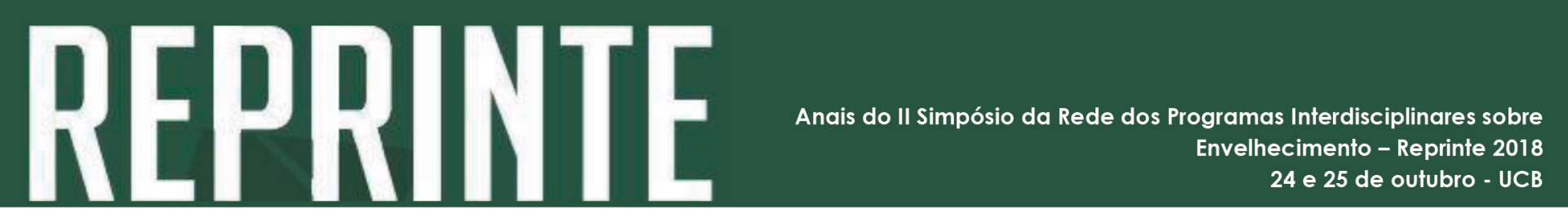

http://dx.doi.org/10.5335/rbceh.v16i1.9852

\title{
14) Diagnóstico tardio de diabetes mellitus tipo 1 em pessoa idosa - relato de caso
}

Kétuny da Silva Oliveira'; Bárbara Sena Morais Gratão'; Gabriela Rodrigues dos Santos; Ekaterine Apóstolos Dagios; Marianna de Almeida Maciel Frech; Fernanda Silveira Tavares²

\section{Resumo}

Pretende-se expor um relato clínico de diabetes mellitus (DM) tipo 1 de manifestação tardia em uma pessoa idosa, descoberto concomitante a um quadro infeccioso e cetoacidose diabética (CAD).

Palavras-chave: Diabetes mellitus; pessoa idosa; diagnóstico tardio.

\section{0 estudo de caso}

Paciente masculino, 75 anos, tabagista há mais de 50 anos, diagnosticado há cerca de 3 anos com Hiperplasia Prostática Benigna, hipertensão arterial, psoríase e hipotireoidismo por doença autoimune, em seguimento ambulatorial no Hospital Anchieta, previamente compensado e sem queixas. Apresentava relatório de internação há 2 semanas com quadro de tosse produtiva, dispneia, febre, queda do estado geral, emagrecimento de $5 \mathrm{~kg}$ em 10 dias, poliúria e polidipsia. Na ocasião, glicemia sérica $448 \mathrm{mg} / \mathrm{dl}$ (VR entre 70 a 99, em jejum), hemograma com leucocitose $25000 / \mathrm{mm}^{3}$ (VR 3000 a 10500) e gasometria arterial com $\mathrm{pH} 2,9$. Recebeu diagnóstico de pneumonia associada à $\mathrm{CAD}$ e alta em insulinoterapia. No momento da consulta em bom estado, exame físico sem alterações e glicemia capilar de $335 \mathrm{mg} / \mathrm{dl}$ (1h pós-prandial). O esquema insulínico foi então mudado e foram solicitados outros exames complementares destando-se alterados hemoglobina glicada 11,2\% (VR até 5,7) e AntiGAD 1994 UI/ml (VR até 10). Foi confirmado, portanto, o diagnóstico de DM1 de manifestação tardia. Outros dados: glicemia 3 meses antes da internação e hemoglobina glicada normais. Sem uso de medicamentos imunossupressores ou hiperglicemiantes em potencial.

1 Graduandos em Medicina da Universidade Católica de Brasília (UCB). Endereço para correspondência: QS 7, Lote 1, Águas Claras, Brasília - CEP: 71966-700, Brasília (DF) Brasil. E-mails: ketunyoliveira@gmail.com; barbara.gratao28@ gmail.com; mlbgabriela@gmail.com; ekaterine_apostolos@hotmail.com; mariannafrech@gmail.com

2 Doutoranda no Programa de Pós-Graduação em Gerontologia, professora da disciplina de Endocrinologia do Curso de Medicina da Universidade Católica de Brasília-DF. E-mail: fernanda.endocrino@gmail.com 


\section{Discussão}

O DM tipo 1 é reconhecido como uma doença que acomete principalmente crianças e adolescentes (ORIOT et al, 2018; DE OLIVEIRA, 2018). Os dados sobre a incidência em pessoas idosas são escassos (ORIOT et al, 2018), porém estudos conduzidos por THUNANDER e colaboradores (2008) revelaram apresentar dois picos de prevalência, o primeiro acontece dos 0-9 anos e o segundo entre 50-80 anos (THUNANDER et al, 2008). A forma de diabetes autoimune tardia que mais acomete adultos é o diabetes autoimune latente do adulto (LADA) (ALVES et al, 2016; LAUGESEN et al, 2015), porém pacientes com este diagnóstico não costumam necessitar de insulina ao diagnóstico, sendo esse um dos critérios diagnósticos (ORIOT et al, 2018; KATAHIRA et al, 2018; ALVES et al, 2016). No presente relato a primeira manifestação foi um quadro de cetoacidose diabética (CAD), ressaltando-se que níveis glicêmicos anteriores eram normais. Ainda que o estado infeccioso possa estar associado à CAD mesmo em DM tipo 2, mais comum nessa faixa etária, o nível elevado do anticorpo anticarboxilase do ácido glutâmico confirmou a etiologia autoimune da doença.

\section{Conclusão}

O DM1 clássico é mais comum na infância e adolescência, mas não é exclusivo dessa população. Tendo em vista o envelhecimento populacional e o exponente crescimento do DM em todo o mundo, cabe o alerta para diagnósticos mais precisos, visando a abordagens terapêuticas mais adequadas. Aos médicos em formação e a todos os profissionais que lidam com a doença, considerar a possibilidade de DM1 em quadros típicos, especialmente se houver antecedentes de outras doenças autoimunes, independente da faixa etária.

\section{Late diagnosis of diabetes mellitus type 1 in older person - case report}

\section{Abstract}

It is intended to expose a clinical report of type 1 diabetes mellitus (DM) of late manifestation in an elderly person, discovered concomitant with an infectious and diabetic ketoacidosis (CAD).

Keywords: Diabetes mellitus; elderly; late diagnosis.

\section{Referências}

ALVES, C.; SANTOS, L.; TORALLES, M,P. Association of type 1 diabetes mellitus and autoimmune disorders in Brazilian children and adolescents. Indian J Endocrinol Metab [Internet]. 2016b; 20(3):381. Available at: http://www.ijem.in/text.asp?2016/20/3/381/179994.

ALVES, D; KACHAN, B.; CARBONI, C; MARIANO, P.; CALMEIRO, M.E.; SILVA, R. LADA numa Unidade Integrada de Diabetes LADA; Diabetes Unit Resumo. 2016a; 23(4):22-5.

CHATZIANAGNOSTOU, K; IERVASI, G; VASSALLE, C. Challenges of LADA Diagnosis and Treatment. Am J Ther [Internet]. 2016;23(5):e1270-4. Disponível em: http://content.wkhealth.com/linkback/openurl?sid=WKPTLP:landingpage\&an=00045391-201609000-00029. 
DE OLIVEIRA, J.E.P. Diretrizes da Sociedade Brasileira de Diabetes 2017-2018. São Paulo: Clannad, 2017.

KATAHIRA, M; OGATA, H; ITO, T.; MIWATA, T.; GOTO, M.; NAKAMURA, S. et al. Association of Autoimmune Thyroid Disease with Anti-GAD Antibody ELISA Test Positivity and Risk for Insulin Deficiency in Slowly Progressive Type 1 Diabetes. J Diabetes Res [Internet]. 2018; 2018:1-7. Available at: https:/www.hindawi.com/journals/ jdr/2018/1847430/.

LAUGESEN, E.; ØSTERGAARD, J.A.; LESLIE, R.D.G. Latent autoimmune diabetes of the adult: Current knowledge and uncertainty. Diabet Med. 2015;32(7):843-52.

ORIOT, P; LOUVET, A; DEBUGNE, G; WEETS, I. Sudden onset of immune-mediated type 1 diabetes mellitus in a 93-year-old woman: a case report. Acta Diabetol [Internet]. 2018;0(0):1-3. Available at: http://dx.doi.org/10.1007/ s00592-018-1170-7

THUNANDER, M; PETERSSON, C; JONZON, K; FORNANDER, J; OSSIANSSON, B; TORN, C. et al. Incidence of type 1 and type 2 diabetes in adults and children in Kronoberg, Sweden. Diabetes Res Clin Pract. 2008;82(2):247-55. 